\title{
Evidence for the Presence of Serotonergic Nerves and Receptors in the Iris-Ciliary Body Complex of the Rabbit
}

\author{
A. B. Tobin, ${ }^{1}$ W. Unger, ${ }^{2}$ and N. N. Osborne ${ }^{1}$ \\ 'Nuffield Laboratory of Ophthalmology, Oxford University, Oxford OX2 6AW, and Institute of Ophthalmology, London \\ WC1H 9QS, United Kingdom
}

The rabbit iris-ciliary body contains $78 \pm 6 \mathrm{ng} / \mathrm{gm}$ serotonin (5-HT) while the amine content in the aqueous humor is less than $0.01 \mathrm{ng} / 100 \mu \mathrm{l}$. The low levels of endogenous $5-\mathrm{HT}$ in the iris-ciliary body could not be directly detected by immunocytochemistry. However, pretreatment in vivo and in vitro with L-tryptophan and pargyline resulted in the localization of a sparse population of 5-HT fibers. These fibers could not be studied by exposing the tissue to exogenous 5-HT since the amine was taken up by noradrenergic fibers as well. This was confirmed in studies involving superior cervical ganglionectomy. It is concluded that 5-HT is taken up by both serotonergic and adrenergic fibers of the irisciliary body.

In the presence of lithium, 5-HT stimulated an increase in the ${ }^{3} \mathrm{H}$-inositol phosphate accumulation in a dose-dependent manner in tissue where the phosphoinositide pool was labeled with ${ }^{3} \mathrm{H}$-inositol. A variety of agonists and antagonists were used to show that the 5-HT response is mediated, at least partly, by $5-\mathrm{HT}_{2}$ receptors. The $5-\mathrm{HT}$-mediated effect on inositol phosphates is unaffected by superior cervical ganglionectomy. The effect of noradrenaline, which also stimulates inositol phosphate accumulation (but via $\alpha_{1}$-adrenergic receptors in the iris-ciliary body), was elevated following superior cervical ganglionectomy.

Serotonin $(5-\mathrm{HT})$ is thought to have a transmitter function in both central and peripheral nervous tissues (Osborne, 1982; Green, 1985). Both forms of nervous tissue exist in the eye. A transmitter role for 5-HT in the retina, part of the central nervous system (CNS) is now well established (Osborne, 1984). In contrast, the evidence for 5-HT having a role in the iris-ciliary body, part of the peripheral nervous system (PNS), is less conclusive. 5-HT and its metabolites have been detected in the cornea biochemically (Klyce et al., 1982; Uusitalo et al., 1982), where 5 -HT has been shown to be taken up by specific nerve fibers (Osborne and Tobin, 1987). Furthermore, immunoreactivity for 5-HT has been demonstrated in corneal stroma and epithelium (Osborne, 1983). In addition, autoradiographic studies have demonstrated binding sites for 5-HT at the corneal epithelium (Palkama et al., 1984). These binding sites may be

\footnotetext{
Received Sept. 14, 1987; revised Nov. 25, 1987; accepted Dec. 29, 1987

We would like to thank the Wellcome Trust for their financial support.

Correspondence should be addressed to Dr. N. N. Osborne, Nuffield Laboratory of Ophthalmology, University of Oxford, Walton Street, Oxford OX2 6AW, U.K. Copyright (C) 1988 Society for Neuroscience $0270-6474 / 88 / 103713-09 \$ 02.00 / 0$
}

physiologically important since exogenous application of 5-HT to the corneal epithelium increases both cAMP levels and chloride ion transport (Klyce et al., 1982; Neufeld et al., 1982).

A transmitter role for 5-HT in the iris-ciliary body was originally implicated by the finding that intravenous injection of the amine in dogs and rabbits lowers their intraocular pressure (Schumacher and Classen, 1962; Chiang, 1974), whilc in the rat a strong constriction of the retinal blood vessels was reported (Tammisto, 1965). Recently it was shown that when 5-HT was injected into the rabbit anterior chamber, not only was the intraocular pressure increased but so was the protein concentration (Palkama et al., 1984). A sparse distribution of serotonergic fibers in the ciliary processes of the guinea pig and rat has been described by Uusitalo et al. (1982) following administration of L-tryptophan. Moreover, when the iris-ciliary body is exposed to exogenous 5-HT, the amine is taken up by a more widespread distribution of fibers (Osborne and Tobin, 1987).

The purpose of the present study is to provide additional information in support of 5-HT having a functional role in the iris-ciliary body of the rabbit. Experiments were conducted (1) to investigate the nature of fibers that accumulate exogenous 5-HT, (2) to report on the presence of 5-HT-immunoreactive fibers following pretreatment with $\mathrm{L}$-tryptophan and pargyline, and (3) to provide evidence for the occurrence of 5-HT receptors linked to the mobilization of the second messenger, inositol trisphosphate.

\section{Materials and Methods \\ Chemicals}

${ }^{3} \mathrm{H}$-inositol $(19.6 \mathrm{Ci} / \mathrm{mm})$ was obtained from Amersham Int. UK, prazosin from Pfizer UK, methysergide from Sandoz, Switzerland, and ketanserin from Janssen Pharmaceuticals, Germany. The 5-HT 3 antagonist MDL 72222 was a kind gift from Dr. Fozard. All other chemicals were obtained from Sigma.

\section{Treatment of animals}

In all experiments adult albino rabbits $(1.5-2 \mathrm{~kg})$ were anesthetized with an intramuscular injection of Hypnorm $(0.5 \mathrm{ml} / \mathrm{kg}$; Janssen $)$ and killed with an overdose of sodium pentabarbitol. Eyes were enucleated immediately and the iris-ciliary body removed.

\section{High-performance liquid chromatography (HPLC)}

Freshly dissected iris-ciliary bodies were washed in physiological saline and immediately homogenized in $0.4 \mathrm{M}$ perchloric acid. Following centrifugation $(5000 \times g$ for $10 \mathrm{~min})$, the supernatant was analyzed by HPLC with electrochemical detection. The apparatus was equipped with a $\mathrm{C}-18$ reverse-phase column and LC-4 amperometric detector. The electrochemical detector was set at $2 \mathrm{nA} / \mathrm{V}$ with a potential of $0.8 \mathrm{~V}$. The mobile phase was $0.02 \mathrm{~m}$ sodium citrate buffer, pH 3.7, containing $0.2 \mathrm{~mm}$ octane-1-sulfonic acid and $6.5 \%$ methanol. 

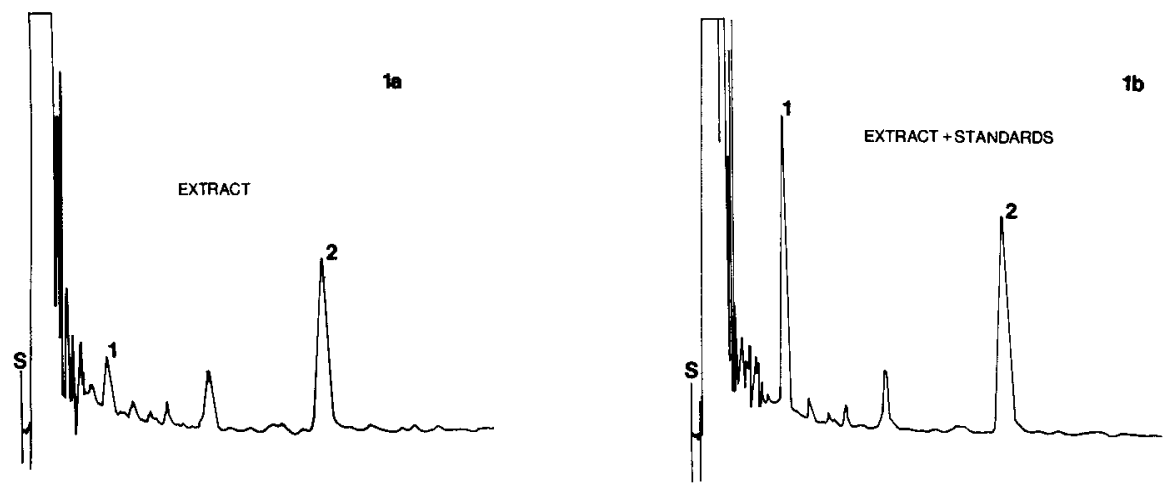

Figure 1. HPLC separation and electrochemical detection of 5-HT in perchloric acid extracts of the iris-ciliary body $(a)$ and aqueous humor $(c)$. Peaks corresponding to the position of dopamine $(I)$ and 5-HT (2) were identified by addition of internal standards to the iris-ciliary body extract $(b)$ and aqueous humor extract $(d)$.
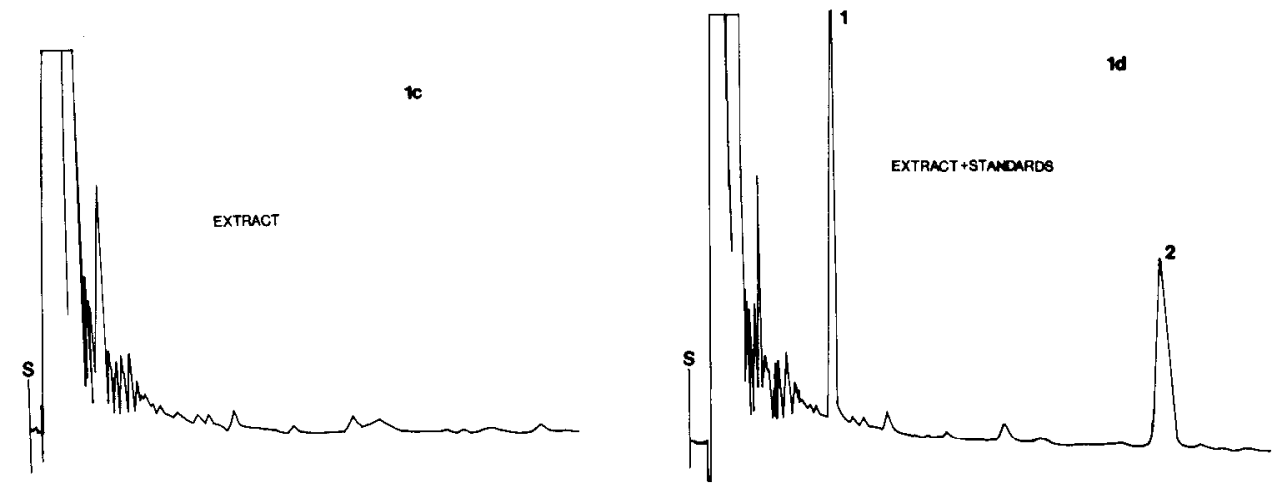

\section{Immunocytochemistry}

The iris-ciliary bodies were fixed in $4 \%$ paraformaldehyde made up in $0.1 \mathrm{M}$ phosphate buffer ( $\mathrm{pH} 7.2$ ) overnight and kept in phosphate buffer containing $30 \%$ sucrose for periods of up to $5 \mathrm{hr}$. Ten micrometer frozen sections were obtained at $-20^{\circ} \mathrm{C}$ and recovered on gelatin-coated glass slides. The sections were then incubated overnight at $4^{\circ} \mathrm{C}$ with a rat $\times$ rat monoclonal antibody (Consolazione et al., 1981) and then developed with a rat anti-rat $\mathrm{IgG}$ conjugated with fluoroscein isocyanate (Miles U.K.). The monoclonal and development fluorescent antibodies were diluted to $1: 100$ and 1:20, respectively, in PBS containing $0.2 \%$ Triton $\mathrm{X}-100$. The glycerol/PBS-mounted sections were observed with a microscope equipped with epifluorescence optics, and photographs were taken with Kodax Tri-X film (400 ASA).

\section{Accumulation of exogenous 5-IIT}

Iris-ciliary bodies were placed in oxygenated Krebs bicarbonate medium $\left(\mathrm{NaCl}, 154 \mathrm{~mm} ; \mathrm{KCl}, 6.17 \mathrm{~mm} ; \mathrm{CaCl}_{2} \cdot 2 \mathrm{H}_{2} \mathrm{O}, 2.50 \mathrm{~mm} ; \mathrm{KH}_{2} \mathrm{CO}_{3}, 1.50\right.$ $\mathrm{mm} ; \mathrm{MgSO}_{4} \cdot 7 \mathrm{H}_{2} \mathrm{O}, 1.50 \mathrm{~mm} ; \mathrm{NaHCO}_{3}, 32.0 \mathrm{~mm}$; glucose, $15.0 \mathrm{~mm}$ ) containing ascorbate $(0.1 \mathrm{mM})$. After a preincubation period of $10 \mathrm{~min}$, $0.1 \mu \mathrm{M} 5-\mathrm{HT}$ and the monoamine oxidase inhibitor pargyline $(10 \mu \mathrm{M})$ were added and the incubation continued for a further $30 \mathrm{~min}$. In some instances, the 5-HT uptake inhibitor chlorimipramine $(10 \mu \mathrm{M})$ (Shaskan and Snyder, 1970) or the catecholamine uptake inhibitor desipramine (Carlsson et al., 1968), as well as noradrenaline (0.1 mM) or dopamine $(0.1 \mathrm{~mm})$, were added during the $10 \mathrm{~min}$ preincubation period. In the case of experiments carried out in a sodium-free medium, the $\mathrm{NaCl}$ and $\mathrm{NaHCO}_{3}$ were replaced with equimolar amounts of sucrose and $\mathrm{KHCO}_{3}$, respectively. After incubation, the tissue was removed, rinsed in cold Krebs bicarbonate medium, and fixed for immunocytochemistry.

\section{Pretreatment with L-tryptophan and pargyline}

In vitro. Iris-ciliary bodies were placed in a Krebs bicarbonate medium that was continuously oxygenated $\left(95 \% \mathrm{O}_{2} / 5 \% \mathrm{CO}_{2}\right)$. The solution contained L-tryptophan $(0.1 \mu \mathrm{M})$ and pargyline $(10 \mu \mathrm{M})$. Following an incubation at $37^{\circ} \mathrm{C}$, the tissue was removed and fixed for immunocytochemistry.

In vivo. An intraperitoneal $(500 \mu 1)$ and intraocular injection into the posterior chamber $(50 \mu \mathrm{l})$ of L-tryptophan $(26 \mathrm{~mm})$ and pargyline $(10$ $\mu \mathrm{M})$ was made and repeated $18 \mathrm{hr}$ later. One hour after the second injection, the animal was sacrificed and the iris-ciliary body fixed for immunocytochemistry.

\section{5-HT stimulation of inositol phosphates accumulation}

Iris-ciliary bodies were dissected and cut into approximately 7 equal pieces (4-6 mg each) and placed in $10 \mathrm{ml}$ oxygenated HEPES-Ringer buffer $\left(\mathrm{NaCl}, 150 \mathrm{~mm} ; \mathrm{KCl}, 5.0 \mathrm{~mm} ; \mathrm{MgSO}_{4} \cdot 7 \mathrm{H}_{2} \mathrm{O}, 1.2 \mathrm{~mm} ; \mathrm{CaCl}_{2}\right.$. $2 \mathrm{H}_{2} \mathrm{O}, 1.2 \mathrm{~mm}$; HEPES, $20 \mathrm{~mm}$; glucose, $15 \mathrm{~mm}$ ). Following an incubation period of $30 \mathrm{~min}$, the medium was renewed with the addition ${ }^{3} \mathrm{H}$-inositol $(0.26 \mu \mathrm{M})$ and incubated for $1 \mathrm{hr}$. The iris-ciliary body pieces were washed in a HEPES-Ringer buffer containing $10 \mathrm{~mm} \mathrm{Li}^{+}$. Each iris-ciliary body piece was then removed with forceps placed in an homogenizing tube containing $300 \mu \mathrm{l} \mathrm{HEPES-Ringer/LiCl}$ buffer and incubated for $10 \mathrm{~min}$ in a shaking water bath $\left(37^{\circ} \mathrm{C}\right)$. During this period, antagonists were added as required. Agonists were then added to the homogenizing tubes and the incubation continued for a further $30 \mathrm{~min}$. The tubes were then placed on ice, and the tissue was removed, rapidly weighed, replaced, and then homogenized in the incubation medium. Immediately after homogenization, separation of the inositol phosphates was carried out by the anion-exchange chromatography method described by Berridge et al. (1982). To each sample $1 \mathrm{ml}$ of methanol/ chloroform $(2: 1, \mathrm{vol} / \mathrm{vol})$ and $500 \mu \mathrm{l}$ of chloroform were added. The phases were allowed to separate, and $1 \mathrm{ml}$ of the aqueous phase was removed; Dowex $(1 \mathrm{ml})$, in the formate form, and distilled water $(2 \mathrm{ml})$ was added to this aqueous phase. The Dowex was allowed to settle and the supernatant removed. The Dowex was then washed 3 times with distilled water. Dissociation of the bound inositol phosphates was achieved by two $500 \mu 1$ elutions with $0.1 \mathrm{M}$ formic acid/ $1 \mathrm{~m}$ ammonium formate. The 2 elutions were combined, and $7 \mathrm{ml}$ of Instagel scintillant (Parkard) was added.

\section{Sympathetic denervation}

Surgical removal of the superior cervical ganglion on the right side was carried out as described by Zhang et al. (1984). The contralateral side served as the control. The animals were sacrificed $26-30 \mathrm{~d}$ postoperatively.

Statistical analysis was performed using Student's paired $t$ test. 

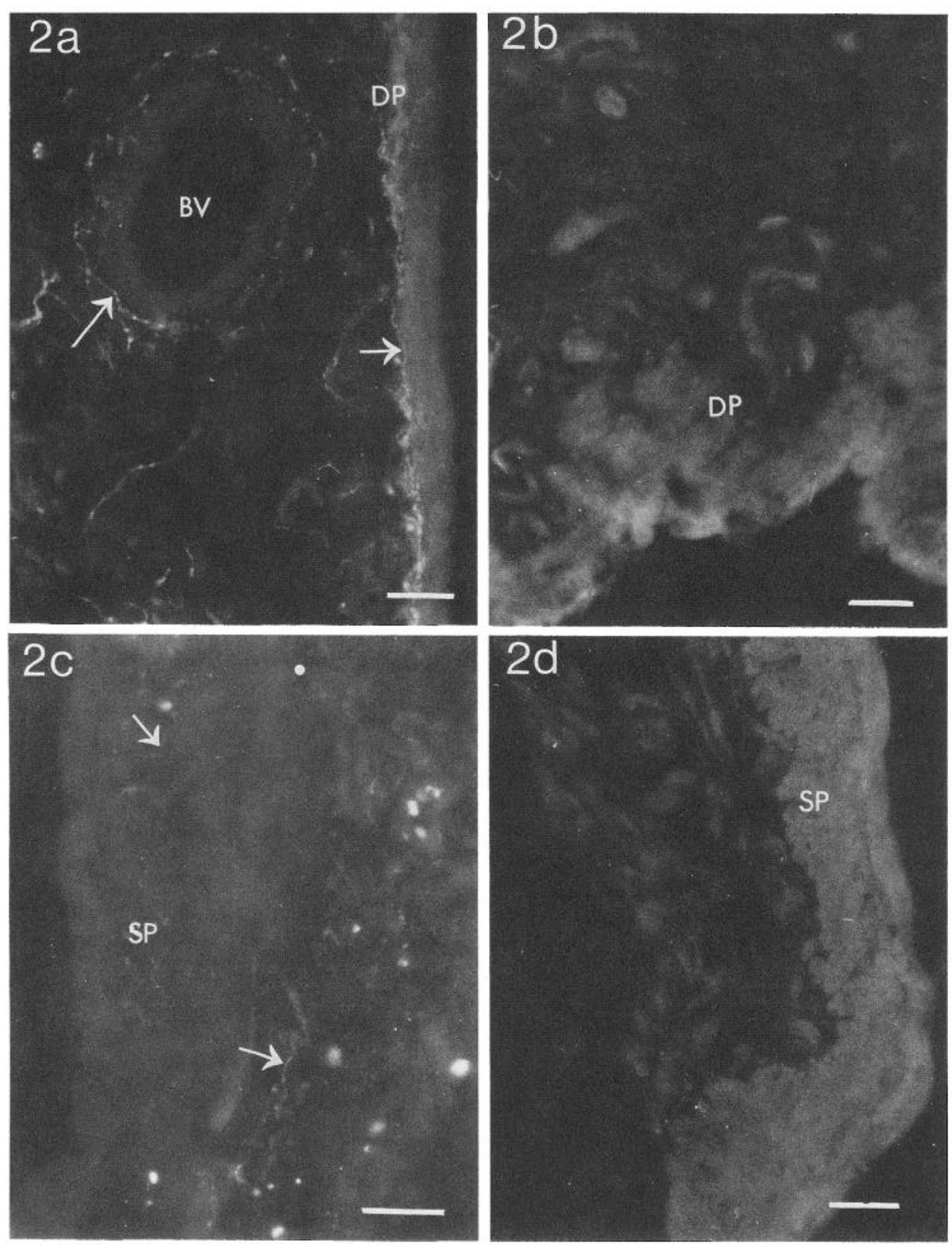

Figure 2. a, Immunocytochemical localization of 5-HT in the dilator region (arrows) after incubation of irisciliary body in a medium containing L-tryptophan and pargyline. $b$, Control iris-ciliary body incubated in Krebs bicarbonate buffer only. $c$, Immunocytochemical localization of 5-HT in the sphincter region (arrow) after intraperitoneal and intraocular injection of L-tryptophan and pargyline. $d$, Control iris-ciliary body from contralateral eye. $B V$, Blood vessels; $D P$, dilator pupillae; $S P$, sphincter pupillae. $B a r=100 \mu \mathrm{m}$.

\section{Results}

\section{Detection and localization of 5-HT}

Figure $1 a$ shows the separation and electrochemical detection of 5-HT from a crude perchloric acid extract of the iris-ciliary body. The 5-HT and dopamine peaks were identified by the addition of internal standards to the extracts (Fig. 1b). From these studies the 5 -HT content was found to be $78 \pm 6 \mathrm{ng} / \mathrm{gm}$ $(n=4, \pm \mathrm{SEM})$. In order to eliminate the aqueous humor as a possible source of 5-HT, an analysis of the 5-HT content was carried out. A peak corresponding to 5-HT was not present in extracts of aqueous humor (Fig. 1, $c, d$ ). It may therefore be concluded that if 5-HT does occur in the aqueous humor, it is at concentrations $<0.01 \mathrm{ng} / \mathrm{gm} / 100 \mu \mathrm{l}$ of aqueous. Thus, the aqueous humor does not seem to be the source of 5-HT identified in the iris-ciliary body extract.

Iris-ciliary body processed for the presence of endogenous
5-HT provided no immunostaining. The only way to obtain positive immunostaining for 5-HT was to pretreat the tissue, either in vitro or in vivo with L-tryptophan and pargyline. However, the results from these procedures varied from experiment to experiment. Figure $2 b$ shows the distribution of 5-HT-immunoreactive fibers in iris-ciliary body preparation following in vitro treatment with L-tryptophan and pargyline. The immunofluorescence was not intense and, because of the variation between preparations, it was difficult to describe the distribution of fibers accurately. Immunoreactive cell bodies were not observed. Following intraocular and intraperitoneal injection of L-tryptophan and pargyline, 5-HT-immunoreactive fibers could be observed in the iris-ciliary body, especially in the sphincter region (Fig. 2c), despite an apparent increase in the nonspecific immunofluorescence.

Tissue first exposed to exogenous 5-HT and then processed immunocytochemically for the localization of the amine re- 

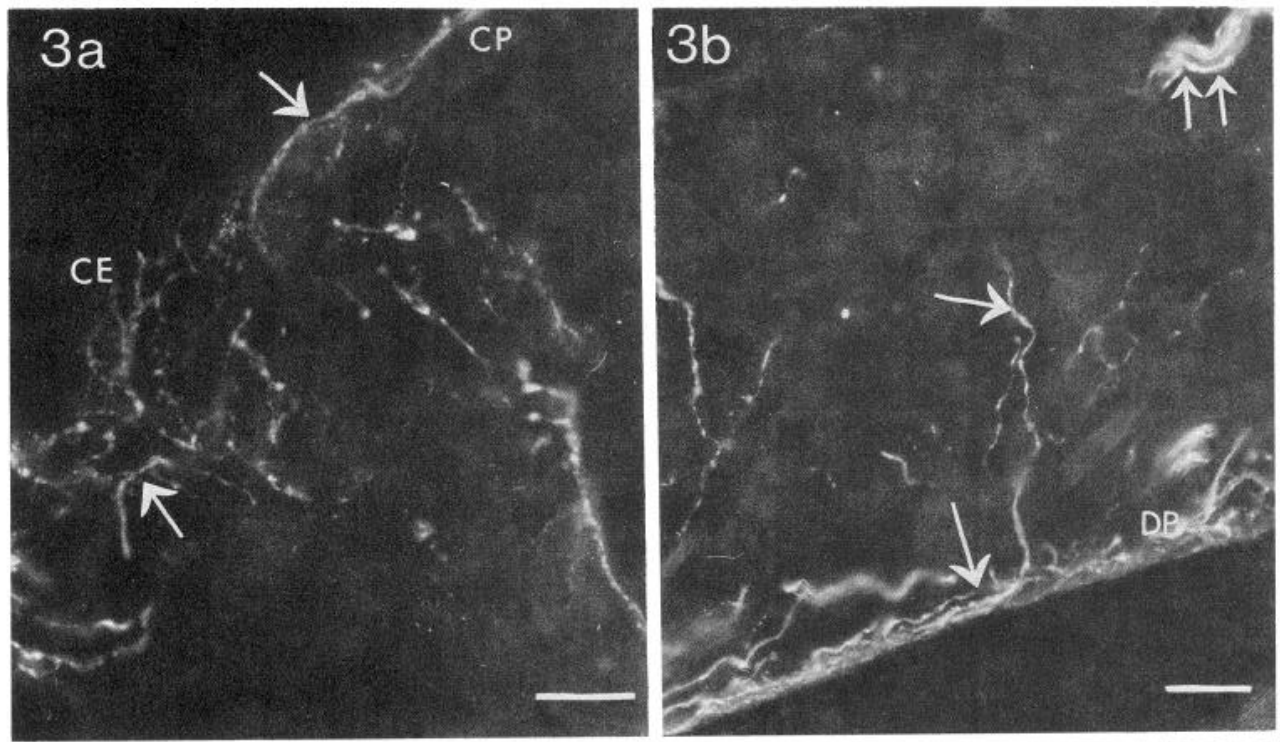

Figure 3. Immunocytochemical localization of 5-HT in the iris-ciliary body following incubation with exogenous 5-HT. $a$, Immunoreactive fibers can be seen beneath the ciliary epithelium $(C E)$ that extend into the ciliary processes $(C P)$. $b$, Plexus of fibers can be seen to run the entire length of the dilator-pupillae $(D P)$. Fibers could also be seen within bundles (double arrow) or as single fibers (single arrow) in the stroma of the dilator. $c$, Plexus of fibers was seen associated with the blood vessels $(B V)$ of the iris. $d$, In the sphincter region, fibers could be seen anterior and posterior to the sphincter pupillae $(S P)$ and within the muscle itself. Scale bar, $100 \mu \mathrm{m}$.
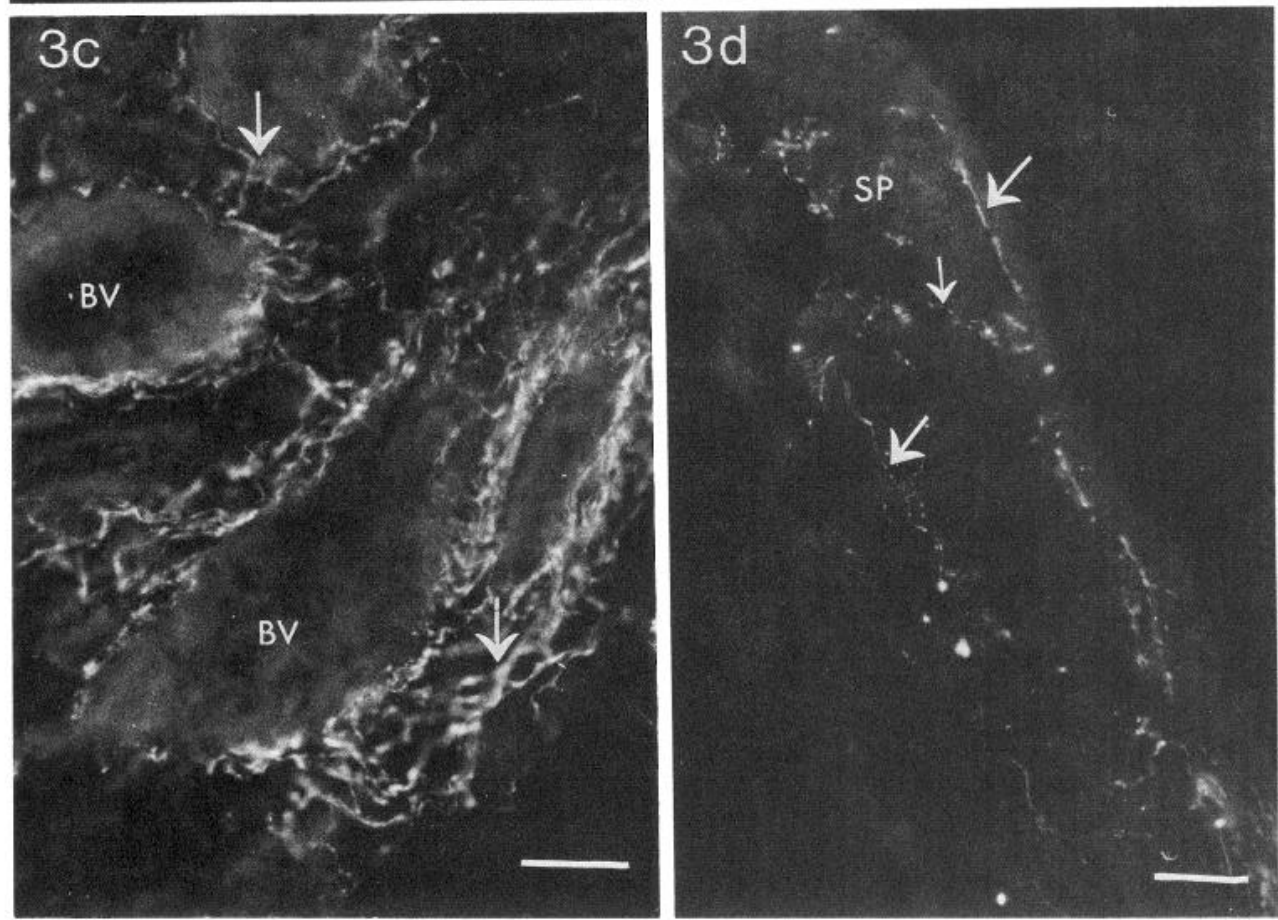

vealed a widespread accumulation (Fig. 3). In the ciliary body a fine network of varicosed fibers beneath the ciliary epithelium was seen to extend into the ciliary processes (Fig. 3a). In the iris a thick plexus of immunoreactive fibers was seen to run the entire length of the dilator, closely associated with the dilator pupillae (Fig. $3 b$ ), and within the stroma, large immunoreactive fiber bundles, together with a sparse population of single varicosed fibers, could be seen (Fig. $3 b$ ). Blood vessels of the iris were also associated with a fine network of single varicosed immunoreactive fibers (Fig. $3 c$ ).

The density of 5-HT-accumulating fibers in the sphincter region was less than that found in the dilator region. Immunoreactive fibers were seen anterior and posterior to the sphincter pupillae. A sparse population of immunoreactive fibers could be seen within the muscle itself (Fig. 3d).

\section{Nature of fibers taking up exogenous 5-HT}

When tissue was exposed to 5 - $\mathrm{HT}$ in vitro at $1^{\circ} \mathrm{C}$ and then processed for the immunocytochemical localization of the amine, the immunoreactive fibers were barely visible. This observation demonstrated that the uptake of 5-HT into the iris-ciliary body was temperature dependent. Similar studies showed the transport of the amine to be dependent on sodium in the incubation medium and inhibited by chlorimipramine. While the uptake of 5-HT was unaffected by high concentrations of dopamine $(0.1 \mathrm{~mm})$ in the incubation medium, the same amount of noradrenaline significantly decreased the amount of 5-HT taken up. Furthermore, the catecholamine uptake inhibitor desipramine inhibited the uptake of 5-HT. In view of the known adrenergic innervation of the iris-ciliary body, this observation 

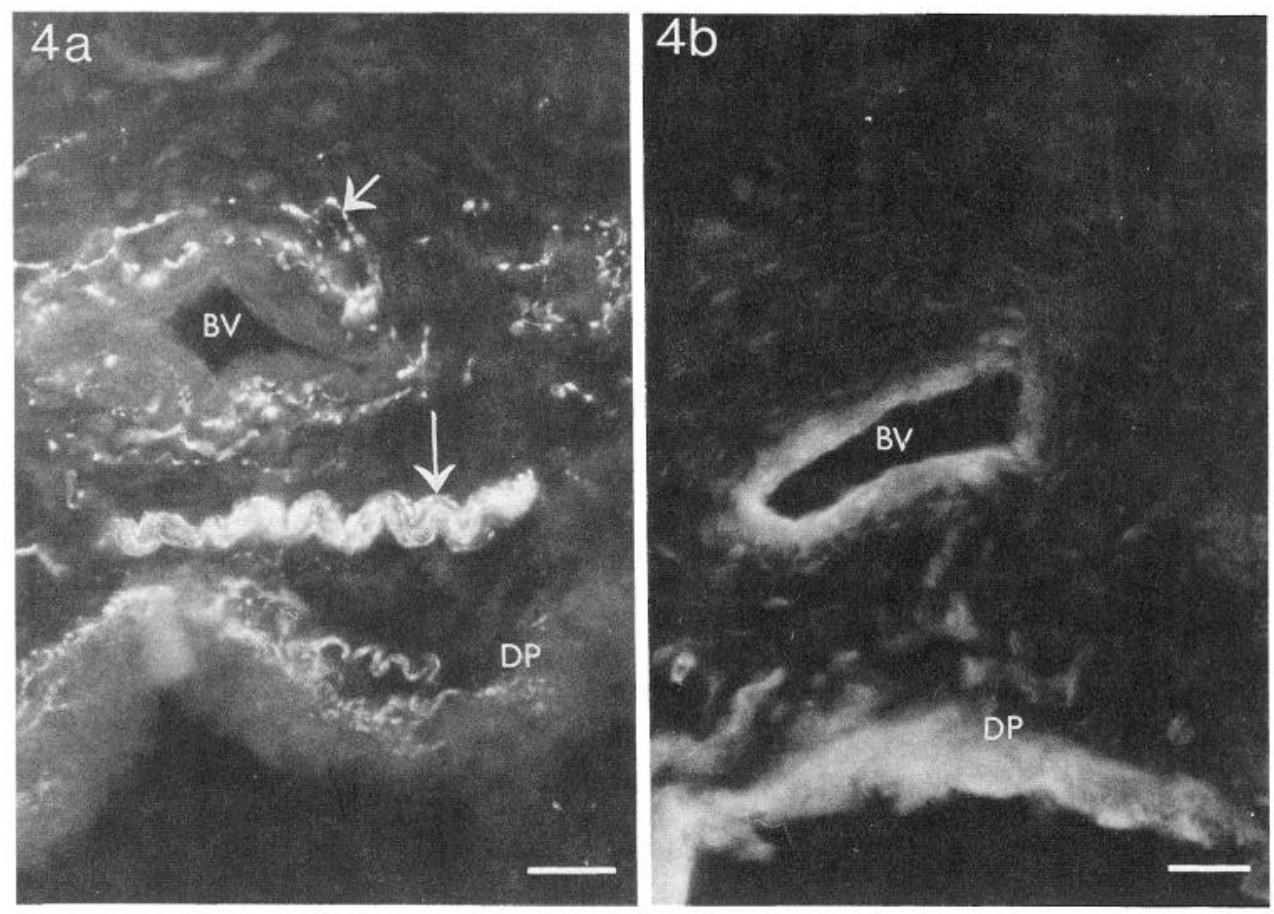

Figure 4. Immunocytochemical localization of 5-HT-accumulating fibers in the dilator region after sympathetic denervation. $a$, Control dilator region. $b$, Ipsilateral sympathetically denervated dilator region. $B V$, Blood vessels; $D P$, dilator pupillae. Scale bar, $100 \mu \mathrm{m}$.

suggested that 5 -HT is taken up by noradrenergic nerves. This postulation receives support from an analysis of 5-HT uptake in sympathetically denervated iris-ciliary bodies. Figure 4, $a, b$, shows sections of denervated tissue processed immunocytochemically for the localization of 5-HT-accumulating fibers. These fibers were almost completely absent.

\section{5-HT stimulation of inositol phosphate accumulation}

5-HT stimulated the accumulation of inositol phosphates in a dose-dependent manner (Fig. 5). The concentration of 5-HT required for half-maximal stimulation $\left(\mathrm{EC}_{50}\right)$ was $50.1 \mu \mathrm{M}$. The effects of various antagonists on the 5-HT-induced accumulation of inositol phosphates is shown in Figure 6. Ketanserin, a specific 5- $\mathrm{HT}_{2}$-receptor antagonist (Leysen et al., 1982), was the most potent inhibitor of the substances tested. Methysergide, which has a higher affinity for the $5-\mathrm{HT}_{2}$ - than the $5-\mathrm{HT}_{1}$-receptor, also partially inhibited the 5-HT response, whereas the peripheral 5- $\mathrm{HT}_{3}$ antagonist MDL 72222 (Fozard, 1984) and

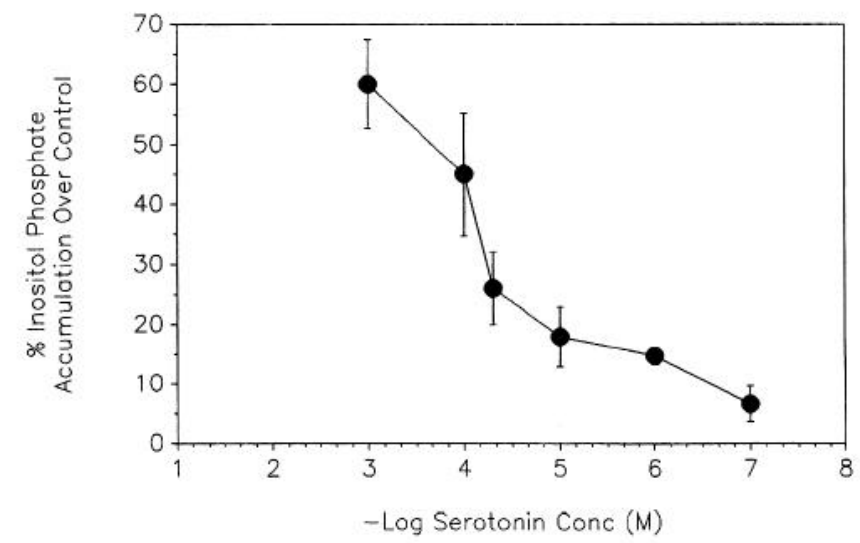

Figure 5. Dose-response curve for 5-HT-stimulated accumulation of inositol phosphates $( \pm \mathrm{SEM}, n=3)$. Each experiment was carried out in triplicate. cyproheptadine had no effect (Fig. 6). The effect of ketanserin and methysergide was analyzed further (Fig. 7), and the $\mathrm{IC}_{50}$ values for the antagonists were found to be 0.49 and $1.99 \mu \mathrm{M}$, respectively.

The effect of 5-HT in comparison with other indole derivatives in stimulating the accumulation of inositol phosphates is shown in Table 1. L-Tryptophan and 5-hydroxytryptophan had no effect at the concentration used, whereas 5-methoxytryptamine and tryptamine stimulated the accumulation of inositol phosphates, but to a lesser extent. The $5-\mathrm{HT}_{\mathrm{la}}$-receptor agonist 8-OH-DPAT (Middlemiss and Fozard, 1983) had no effect on the stimulation of inositol phosphates.

Consistent with previous studies by Akhtar and Abdel-Latif (1984), noradrenaline and carbachol stimulated inositol phosphates accumulation in the iris-ciliary body (Table 1). Neither

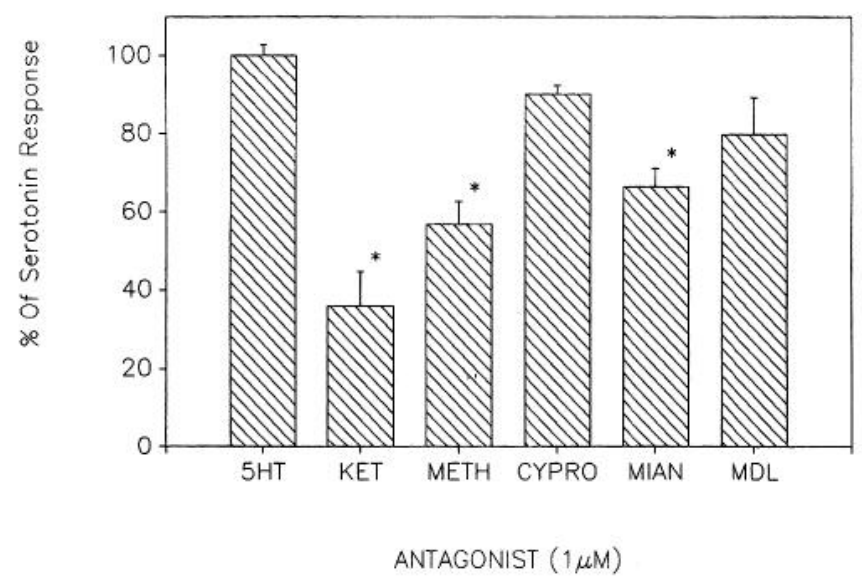

Figure 6. Effects of 5-HT-receptor antagonists on the 5-HT (1 mм) stimulated accumulation of inositol phosphates $( \pm \operatorname{SEM}, n=3)$. Each experiment was carried out in triplicate. $5 H T$, serotonin; $K E T$, ketanserin; $M E T H$, methysergide; $C Y P R O$, cyproheptadine; $M I A N$, mianserin; $M D L$, MDL 72222. * $p<0.05$ (Student's paired $t$ test). 


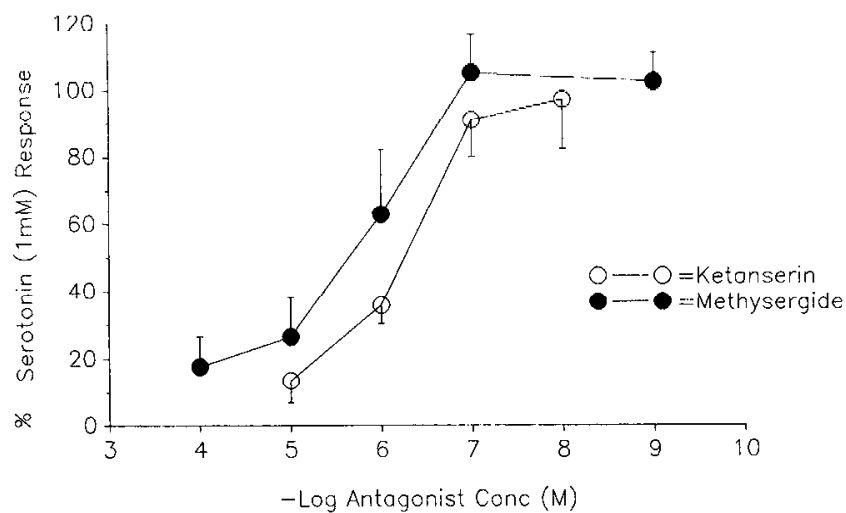

Figure 7. Inhibition of 5-HT (1 mM) stimulated accumulation of inositol phosphates by ketanserin and methysergide $( \pm \mathrm{SEM}, n=3)$. Each experiment was carried out in triplicate.

the muscarinic (atropine) nor the $\alpha_{1}$-adrenergic (prazosin) antagonists had any effect on the 5-HT response (Fig. 8). These data show that the 5-HT response is mediated via receptors that are distinct from $\alpha_{1}$-adrenergic and muscarinic cholinergic receptors.

Manifestation of an $\alpha_{1}$-adrenergic supersensitivity following sympathetic denervation has been demonstrated previously in rabbit iris smooth muscle (Abdel-Latif et al., 1978; Akhtar and Abdel-Latif, 1986). This was illustrated by a left-hand shift in the dose-response curve to noradrenaline-stimulated inositol phosphate accumulation (Akhtar and Adbel-Latif, 1986). These findings were confirmed in this study by a $152 \pm 6.0 \%(n=3)$ increase in the noradrenaline response in the sympathetically denervated iris-ciliary body over that seen in the contralateral iris-ciliary body. However, surgical removal of the superior cervical ganglion had no effect on the 5-HT response (Fig. 9).

\section{Discussion}

Following the intraperitoneal injection of L-tryptophan and pargyline, Uusitalo et al. (1982) were able to localize 5-HT immunoreactivity in the iris-ciliary body and cornea of the rat and guinea pig. Together with the identification of 5-HT in the bovine cornea (Osborne, 1983) and the presence of 5-HT receptors linked to adenylate cyclase in the rabbit corneal epithelium

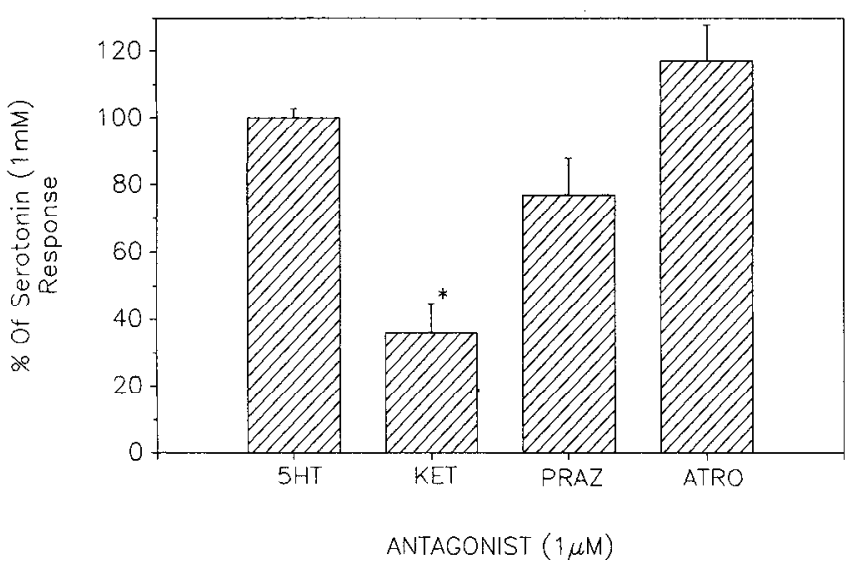

Figure 8. Effects of atropine $(A T R O, 1 \mu \mathrm{M})$, prazosin $(P R A Z, 1 \mu \mathrm{M})$, and ketanserin $(K E T, 1 \mu \mathrm{M})$ on the 5-HT (1 mM) stimulated accumulation of inositol phosphates ( \pm SEM, $n=3$ ). Each experiment was carried out in triplicate. ${ }^{*} p<0.05$ (Student's paired $t$ test).

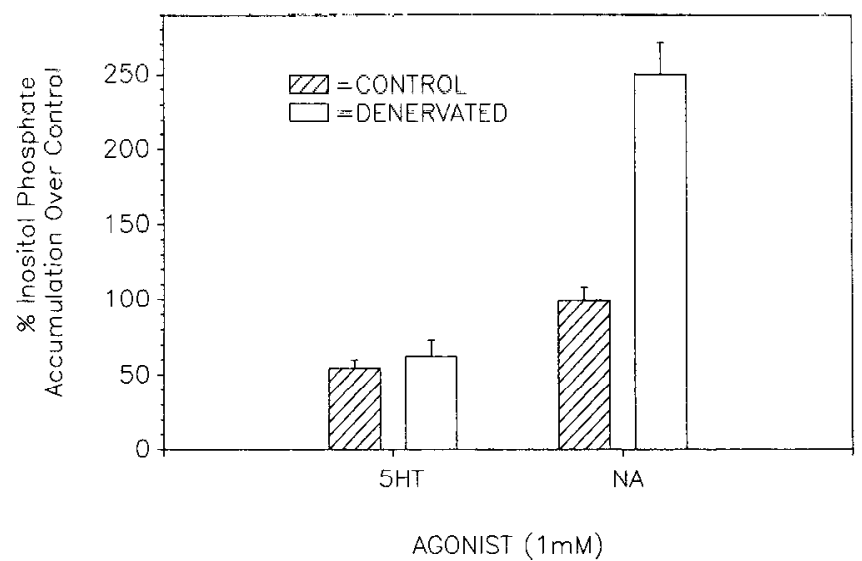

Figure 9. Effects of surgical sympathetic denervation on the 5-HT (1 $\mathrm{mm})$ and noradrenaline $(N A, 1 \mathrm{~mm})$ mediated accumulation of inositol phosphates $( \pm \mathrm{SEM}, n=3)$. Each experiment was carried out in triplicate.

(Neufeld et al., 1982, 1983), this suggests a role for 5-HT in the anterior segment of the eye. The present study was an attempt to confirm that 5-HT has a functional role in the iris-ciliary body.

\section{Uptake of exogenous 5-HT}

Reverse-phase HPLC analysis of rabbit iris-ciliary body extract demonstrated the presence of low levels of 5-HT $(78 \pm 6 \mathrm{ng}$ / $\mathrm{gm}$ ). Using the indirect immunofluorescent technique (Coons, 1958 ) with a primary monoclonal antibody to 5-HT (Consolazione et al., 1981), attempts to localize endogenous 5-HT were unsuccessful. This was attributed to the inability of the immunofluorescent technique to detect such low levels of the amine (see Osborne et al., 1982). This situation parallels that found in the mammalian retina, where serotonergic fibers could only be localized after loading with exogenous 5-HT (Osborne, 1980; Mitchell and Redburn, 1985). Adoption of this approach revealed an extensive distribution of 5-HT-accumulating fibers in the iris-ciliary body. The density of these fibers was far higher than might have been anticipated from the endogenous levels of 5-HT measured by HPLC. The distribution of 5-HT-accumulating fibers was similar to that reported for the sympathetic innervation (Hedlund et al., 1984), which led to the suspicion that 5-HT was accumulated into noradrenergic, as well as any

Table 1. Effect of various substances (concentration, $1 \mathrm{~mm}$ ) on the stimulation of inositol phosphates in the iris-ciliary body

\begin{tabular}{lc} 
Agonist & $\begin{array}{l}\text { Stimulation over } \\
(\%)\end{array}$ \\
\hline Carbachol & $195.40 \pm 14.7$ \\
Noradrenaline & $188.56 \pm 33.7$ \\
5-HT & $59.70 \pm 6.43$ \\
Tryptophan & $10.43 \pm 7.3$ \\
5-Hydroxytryptophan & $-7.95 \pm 4.6$ \\
Tryptamine & $48.08 \pm 6.5$ \\
5-Methoxytryptamine & $36.60 \pm 12.9$ \\
8-OH-DPAT & $-5.50 \pm 6.5$
\end{tabular}

Results expressed as means $\pm \operatorname{SEM}(n=3)$; each experiment was carried out in triplicate. 
serotonergic, fibers. The uptake of 5-HT into noradrenergic fibers is known to occur in the CNS (Lichtensteiger et al., 1967; Iversen, 1970) and in peripheral tissues (Thoa et al., 1969; JaimEtcheverry and Zieher, 1982), and if this were the case in the iris-ciliary body, it would explain the high density of 5-HTaccumulating fibers. However, there does appear to be a lack of correlation between 5-HT-accumulating fibers and tyrosine hydroxylase-immunoreactive nerves in the iris-ciliary body (Osborne and Tobin, 1987), which may be significant.

5-HT uptake was studied at a concentration of $0.1 \mu \mathrm{M}$, which is below the $K_{m}$ for the low-affinity uptake process, but within the $K_{m}$ for the high-affinity specific uptake mechanism (Shaskan and Snyder, 1970). 5-HT accumulation was found to be sodium and temperature dependent, sensitive to the tricyclic antidepressant chlorimipramine, and unaffected by high concentrations of dopamine $(0.1 \mathrm{~mm})$. These findings are consistent with the properties of the specific uptake process identified at serotonergic nerve terminals (Osborne, 1980; Ross, 1982). However, the presence of noradrenaline $(0.1 \mathrm{~mm})$ or the catecholamine uptake inhibitor desipramine did reduce 5- $\mathrm{HT}$ accumulation, indicating that the transport system for noradrenaline and 5-HT have similar properties.

The complete loss of 5-HT-accumulating fibers following superior cervical ganglionectomy suggests that these fibers originate from the superior cervical ganglion. Since this ganglion is the source of sympathetic innervation of the iris-ciliary body, at least a proportion of the accumulating fibers may therefore be noradrenergic. The possibility that some fibers originating from the superior cervical ganglion are serotonergic is suggested by the report of Verhofstad et al. (1981), in which it was shown that 5-HT-immunoreactive cell bodies exist in the superior cervical ganglion.

It can be concluded from these studies that exogenous 5 -HT may be accumulated into noradrenergic, as well as any serotonergic, fibers in the iris-ciliary body. Hence, unlike the situation in the retina, loading with exogenous 5-HT is not a suitable methodology for the exclusive localization of serotonergic fibers in the iris-ciliary body.

\section{Pretreatment with L-tryptophan and pargyline}

The activity of the rate-limiting enzyme tryptophan hydroxylase (Fernstrom, 1983) is dependent on the L-tryptophan concentration (Fernstrom and Wurtman, 1971). Exposure of the irisciliary body to $0.1 \mathrm{~mm}$ L-tryptophan and the monoamine oxidase inhibitor pargyline, either in vitro or in vivo, resulted in an increase in the intraneuronal levels of 5-HT such that it was possible to detect a sparse population of 5-HT-immunoreactive fibers in the ciliary body, dilator, and sphincter regions. The present data may be interpreted to suggest that the pharmacological treatment increases exogenous levels of 5-HT, which is then taken up by nerves in sufficient quantities for localization. This seems unlikely because only a specific population of 5-HTimmunoreactive fibers are observed, which contrasts with the many fibers revealed following exposure to exogenous 5 -HT (compare Figs. 2 and 3). Instead, we interpret our results to show that following pharmacological treatment the endogenous 5-HT is raised to sufficient levels for immunocytochemical localization within serotonergic nerves.

\section{5-HT-mediated accumulation of inositol phosphates}

Receptor-mediated hydrolysis of membrane polyphosphatidylinositides, due to the activation of a specific phosphodiesterase (phospholipase C), results in the generation of 2 secondary messengers: inositol trisphosphate and diacylglycerol. Diacylglycerol has been shown to activate protein kinase $C$, whereas inositol trisphosphate is thought to initiate the mobilization of calcium from intracellular stores (Berridge, 1984; Abdel-Latif, 1986; Downes, 1986).

Activation of this second messsenger system in the rabbit iris smooth muscle has previously been shown to be mediated by noradrenaline, carbachol (Akhtar and Abdel-Latif, 1984), and substance P (Yousufzai et al., 1986). By using the ability of lithium to block the enzyme myoinositol-1-phosphatase, and hence the recycling of inositol phosphate, this study was able to demonstrate a 5-HT-stimulated accumulation of ${ }^{3} \mathrm{H}$-inositol phosphates from a prelabeled pool of phosphatidylinositides. The 5-HT response was insensitive to atropine and prazosin, indicating that the 5-HT effect is mediated by receptors that are distinct from $\alpha_{1}$-adrenergic and muscarinic cholinergic receptors.

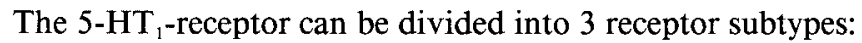
$5-\mathrm{HT}_{1 \mathrm{a}}, 5-\mathrm{HT}_{1 \mathrm{~b}}$, and $5-\mathrm{HT}_{1 \mathrm{c}}$, where the $5-\mathrm{HT}_{1 \mathrm{a}}$ receptors are positively linked to adenylate cyclase (Shenker et al., 1985), 5 - $\mathrm{HT}_{\mathrm{lb}}$ are negatively linked to adenylate cyclase (see Hoyer and Schoeffter, 1988) and 5-HT ${ }_{1 \mathrm{c}}$ are coupled to the hydrolysis of phosphoinositides (Conn et al., 1986). The finding that the potent 5-HT $\mathrm{Ha}_{\mathrm{a}}$-receptor agonist 8-OH-DPAT (Middlemiss and Fozard, 1983) has no stimulatory effect on the inositol phosphates accumulation in the iris-ciliary body eliminates the $5-\mathrm{HT}_{1 \mathrm{a}}$ receptor from being associated with the observed 5-HT-stimulated accumulation of inositol phosphates. Furthermore, the sensitivity of the 5-HT response to ketanserin strongly suggests that the response is not mediated via either $5-\mathrm{HT}_{1 \mathrm{a}^{-}}$or $5-\mathrm{HT}_{1 \mathrm{~b}^{-}}$ receptor subtypes. A recent study on the pig choroid plexus has revealed a $5-\mathrm{HT}_{1 \mathrm{c}}$-receptor that is linked to the hydrolysis of phosphoinositides (Conn et al., 1986). Mianserin was found to have over a 10 -fold greater affinity at the $5-\mathrm{HT}_{1 \mathrm{c}}$ receptor than ketanserin (Conn et al., 1986). It can be seen from Figure 6 that ketanserin has a greater inhibitory effect than mianserin on the 5-HT-stimulated accumulation of inositol phosphates in the iris-ciliary body, indicating that the 5-HT response observed in this study does not act through $5-\mathrm{HT}_{1 \mathrm{c}}$-receptors.

It is of interest to note that the specific peripheral $5-\mathrm{HT}_{3}$ receptor antagonist MDL 72222 was ineffectual in blocking the 5-HT-induced stimulation of inositol phosphates.

The inhibitory actions of ketanserin $\left(\mathrm{IC}_{50}=0.49 \mu \mathrm{M}\right)$ and methysergide $\left(\mathrm{IC}_{50}=1.99 \mu \mathrm{M}\right)$, show that the 5 -HT response is mediated, at least partly, by the $5-\mathrm{HT}_{2}$-receptor subtype. This is consistent with the findings in the cerebral cortex (Conn and Sanders-Bush, 1984, 1985), retina (Cutcliffe and Osborne, 1987), blood platelets (Schachter et al., 1985), and aorta (Roth et al., 1984), where 5-HT has been shown to stimulate the turnover of polyphosphatidylinositides via the $5-\mathrm{HT}_{2}$-receptor subtype. However, the finding that cyproheptadine had no effect on the serotonergic response may indicate that peripheral $5-\mathrm{HT}_{2}$-receptors have slightly different properties from those of central $5-\mathrm{HT}_{2}$ sites.

L-Tryptophan and 5-hydroxytryptophan do not stimulate the accumulation of inositol phosphates. However, levels of inositol phosphates are increased by tryptamine and 5-methoxytryptamine, albeit at a lower potency than 5-HT. Both tryptamine and 5-methoxytryptamine are known to exist in the CNS in tracc amounts (Bosin et al., 1979; Juorio and Greenshaw, 1985) but have not been identified in the iris-ciliary body. 


\section{Effects of sympathetic denervation on the accumulation of inositol phosphates}

Supersensitivity of the noradrenaline response following denervation was observed in the present study and confirms previous reports (Akhtar and Abdel-Latif, 1986). The biochemical mechanism for the induced supersensitivity is unknown, but it has been suggested that it is not due to an increase in the number of $\alpha_{1}$-adrenoreceptors but to an increase in the efficiency of the noradrenaline-stimulated polyphosphatidylinositide turnover (Akhtar and Abdel-Latif, 1986).

Superior cervical ganglionectomy did not, however, affect the 5-HT response, as might have been expected if the serotonergic innervation originated from the superior cervical ganglion. An up-regulation of hippocampal 5- $\mathrm{HT}_{2}$-receptors has been demonstrated following specific lesions (Seeman et al., 1980) and 5,7-dihydroxytryptamine treatment (Morrow et al., 1985). However, clectrolytic lesions of the raphe afferents do not result in the up-regulation of $5-\mathrm{HT}_{2}$-receptors in the hippocampus. Furthermore, studies on the cerebral cortex have demonstrated that $5-\mathrm{HT}_{2}$-mediated phosphoinositide hydrolysis does not show supersensitivity following 5,7-dihydroxytryptamine treatment (Conn and Sanders-Bush, 1986). These studies indicate that the phenomenon of supersensitivity following transmitter depletion is not universal for the serotonergic receptors (Hamon et al., 1984). Therefore, superior cervical ganglionectomy may result in serotonergic denervation but with no associated supersensitivity of the 5-HT-stimulated accumulation of inositol phosphates. For this reason the fact that there is no supersensitivity of the 5-HT response does not eliminate the possibility that the serotonergic innervation of the iris-ciliary body originates from the superior cervical ganglion.

\section{References}

Abdel-Latif, A.A. (1986) Calcium-mobilizing receptors, polyphosphoinositides and the generation of secondary messengers. Pharmacol. Kev. 38: 227-272.

Abdel-Latif, A. A., K. Green, and J. P. Smith (1978) Sympathetic denervation and the triphosphoinositide effect in the iris smooth muscle: A biochemical method for the determination of $\alpha$-adrenergic receptor denervation supersensitivity. J. Neurochem. 32: 225-228.

Akhtar, R. A., and A. A. Abdel-Latif (1984) Carbachol causes rapid phosphodiesteric cleavage of phosphatidylinositol 4,5-bis-phosphate in rabbit iris smooth muscle: Prazosin inhibits noradrenaline and ionophore A23187 stimulated accumulation of inositol phosphates. Biochem. J. 224: 291-300.

Akhtar, R. A., and A. A. Abdel-Latif (1986) Surgical sympathetic denervation increases $\alpha$-adrenoceptor-mediated accumulation of myoinositol triphosphate and muscle contraction in rabbit iris dilator smooth muscle. J. Neurochem. 46: 96-104.

Berridge, M. J. (1984) Inositol trisphosphate and diacylglycerol as secondary messengers. Biochem. J. 220: 345-360.

Berridge, M. J., C. P. Downes, and M. R. Hanley (1982) Lithium amplifies agonist-dependent hydrolysis of membrane phosphoinositides. Biochem. J. 206: 587-595.

Bosin, T. T., G. Jonsson, and O. Beck (1979) On the occurrence of 5-methoxytryptamine in brain. Brain Res. 173: 17379-17388.

Carlsson, A., K. Fux, and U. Ungerstedt (1968) The effects of imipramine on central 5-hydroxytryptamine neurones. J. Pharm. Pharmacol. 20: 150-150.

Chiang, T. S. (1974) Effects of intravenous infusions of histamine, 5-hydroxytryptamine, bradykinin and prostaglandins on intraocular pressure. Ach. Int. Pharmacodyn. 207: 131-138.

Conn, J. P., and E. Sanders-Bush (1984) Selective 5HT-2 antagonists inhibit serotonin stimulated phosphatidylinositol metabolism in the cerebral cortex. Neuropharmacology 23: 993-996.

Conn, J. P., and E. Sanders-Bush (1985) Serotonin-stimulated phosphoinositide turnover mediated by $\mathrm{S} 2$ binding site in rat cerebral cortex but not in subcortical regions. J. Pharmacol. Exp. Ther. 234: 195-203.

Conn, J. P., and E. Sanders-Bush (1986) Regulation of serotoninstimulated phosphoinositide hydrolysis: Relation to serotonin 5HT-2 binding sites. J. Neurosci. 6: 3669-3675.

Conn, J. P., E. Sanders-Bush, B. J. Hoffman, and P. R. Hartig (1986) A unique serotonin receptor in choroid plexus is linked to phosphatidylinositol turnover. Proc. Natl. Acad. Sci. USA 83: 4086-4088.

Consolazione, A., B. Milstein, B. Wright, and A. C. Cuello (1981) Immunocytochemical detection of serotonin with monoclonal antibodies. J. Histochem. Cytochem. 29: 1425-1430.

Coons, A. H. (1958) Fluorescent antibody methods. In General $\mathrm{Cy}$ tochemical Methods, J. F. Danielli, ed., pp. 399-422, Academic, New York.

Cutcliffe, N., and N. N. Osborne (1987) Serotonergic and cholinergic stimulation of inositol phosphate formation in the rabbit retina. Evidence for the presence of 5HT-2 and muscarinic receptors. Brain Res. 421: $95-104$.

Downes, C. P. (1986) Agonist-stimulated phosphatidylinositol 4-5bisphosphate metabolism in the nervous system. Neurochem. Int. 8: 141-154.

Fernstrom, J. D. (1983) Role of precursor availability in control of monoamine biosynthesis in brain. Physiol. Rev. 63: 484-546.

Fernstrom, J. D., and R. J. Wurtman (1971) Brain serotonin content. Physiological dependence on plasma tryptophan levels. Science 173: 149-152.

Fozard, J. R. (1984) MDL 72222: A potent and highly selective antagonist at neuronal 5-hydroxytryptamine receptors. NaunynSchmiedebergs. Arch. Pharmac. 326: 36-44.

Green, A. R. (1985) ed., Neuropharmacology of Serotonin, Oxford U. P., Oxford.

Hamon, M., S. Bourgoin, S. El Mestikawy, and C. Goetz (1984) Central serotonin receptors. In Hand Book of Neurochemistry, Vol. 6, A. Lajtha, ed., pp. 107-143, Plenum, New York.

Hedlund, K-O., A. Ayer-Lelivre, H. Bjorklund, L. Hultgen, and A. Seiger (1984) Ultrastructural and histochemical studies of the rat iris: Identified neuronal inputs and supportive glia. J. Neurocytol. 13: $703-725$.

Hoyer, D. and P. Schoeffter (1988) $5 \mathrm{HT}_{1 \mathrm{D}}$ receptor-mediated inhibition of forskolin-stimulated adenylate cyclase activity in calf substantia nigra. Eur. J. Pharmacol. 147: 145-147.

Iversen, L. L. (1970) Neuronal uptake processes for amine and amino acids. In Advances in Biochemical Psychopharmacology, Vol. 2, Biochemistry of Single Neuronal Models, E. Costa and E. Giacobini, eds., pp. 109-132, Raven, New York.

Jaim-Etcheverry, G., and L. M. Zieher (1982) Coexistence of monoamines in peripheral adrenergic neurones. In Co-transmission, A. C. Cuello, ed., pp. 189-206, MacMillan, London.

Juorio, A. V., and A. J. Greenshaw (1985) Tryptamine concentrations in areas of 5-hydroxytryptamine terminal innervation after electrolytic lesions of raphe nuclei. J. Neurochem. 45: 422-426.

Klyce, S. D., K. A. Palkama, M. Hakmen, W. S. Marshall, K. P. Mann, and A. H. Neufeld (1982) Neuronal serotonin stimulates chloride transport in rabbit corneal epithelium. Invest. Ophthalmol. Vis. Sci. 23: $181-192$.

Leysen, J. E., C. J. E. Niemegeers, J. M. Van Neuten, and P. M. Laduron (1982) $\left({ }^{3} \mathrm{H}\right)$ Ketanserin ( $\left.\mathrm{R} 41468\right)$ a selective $\left({ }^{3} \mathrm{H}\right)$ ligand for serotonin receptor binding sites. Mol. Pharmacol. 21: 301-314.

Lichtensteiger, W., U. Mutzner, and H. Langemann (1967) Uptake of 5 -hydroxytryptamine and 5-hydroxytryptophan by neurones of central nervous system normally containing catecholamines. J. Neurochem. 14: 489-497.

Middlemiss, D. N., and J. R. Fozard (1983) 8-hydroxy-2-(di-n-propylamino) tetran discriminates between subtypes of $5 \mathrm{HT}-1$ recognition sites. Eur. J. Pharmacol. 90: 151-153.

Mitchell, C. K., and D. A. Redburn (1985) Analysis of pre- and postsynaptic factors of the serotonin system in rabbit retina. J. Cell Biol. 100: 64-73.

Morrow, A. L., A. B. Norman, G. Battaglia, R. Loy and I. Crecse (1985) Up-regulation of serotonergic binding sites labeled by $\left({ }^{3} \mathrm{H}\right) \mathrm{WB} 4101$ following fimbrial transection and 5,7-dihydroxytryptamine-induced lesions. Life Sci. 37: 1913-1922.

Neufeld, A. H., S. E. Ledyard, M. M. Klyce, and S. D. Klyce (1982) Serotonin stimulated cAMP synthesis in the rabbit corneal epithelium. Invest. Ophthalmol. Vis. Sci. 23: 193-198. 
Neufeld, A. H., S. E. Ledgard, and B. K. Yoza (1983) Changes in responsiveness of the $\beta$ adrenergic and scrotonergic pathways of the rabbit corneal epithelium. Invest. Ophthalmol. Vis. Sci. $24: 52 \overline{7}-534$.

Osborne, N. N. (1980) In vitro experiments on the metabolism uptake and release of 5-hydroxytryptamine in bovine retina. Brain Res. 184 : 283-291.

Osborne, N. N. (1982) ed., Biology of Serotonergic Transmission, Chichester, U.K.

Osborne, N. N. (1983) The occurrence of serotonin nerves in the bovine cornea. Neurosci. Lett. 35: 15-18.

Osborne, N. N. (1984) Indoleamine in the eye with special reference to the serotonergic neurones of the retina. Progress in Retinal Research, Vol. 3, N. N. Osborne and G. J. Chadar, eds., pp. 61-104, Pergamon, Oxford.

Osborne, N. N., and A. B. Tobin (1987) Serotonin-accumulating cells in the iris-ciliary body and cornea of various species. Exp. Eye Res. 44: 731-746.

Osborne, N. N., T. Nesselhut, D. A. Nicholas, S. Patel, and A. C. Cuello (1982) Serotonin containing neurones in vertebrate retina. J. Neurochem. 39: 1519-1528.

Palkama, A., J. Lehtosalo, and H. Uusitalo (1984) 5-hydroxytryptamine receptors in the cornea and ciliary processes of the rabbit and human eyes. Ophthal. Res. 16: 207-208.

Ross, S. B. (1982) The characteristics of serotonin uptake systems. In Biology of Serotonergic Transmission, N. N. Osborne, ed., pp. 159195, Wiley, Chichester, U.K.

Roth, B. L., T. Nakaki, D-M. Chuang, and E. Costa (1984) Aortic recognition sites for serotonin (5HT) are coupled to phosphatidylinositol turnover. Neuropharmacology 23: 1223-1225.

Schachter, M., P. P. Godfrey, M. C. W. Minchin, S. J. McClue, and M. M. Young (1985) Serotonergic agonists stimulate inositol lipid metabolism in rabbit platelets. Life Sci. 37: 1641-1647.

Schumacher, H., and H. G. Classen (1962) Neuropharmacological studies on the analysis of pupillae motor activity. Von. Graefe. Arch. Ophthalmol. 164: 533-537.
Seeman, P., K. Westman, D. Coscina, and J. J. Warsh (1980) Serotonin receptors in hippocampus and frontal cortex. Eur. J. Pharmacol. 66: 179-191.

Shaskan, E. C, and S. II. Snyder (1970) Kinetics of serotonin accumulation into slices from the rat brain: Relationship to catecholamine uptake. J. Pharmacol. Exp. Ther. 175: 404-418.

Shenker, A., S. Maayani, H. Weinstein, and J. P. Green (1985) Two $5 \mathrm{HT}$ receptors linked to adenylate cyclase in guinea pig hippocampus are discriminated by 5 -carboxytryptamine and spiperone. Eur. J. Pharmacol. 109: 427-429.

Tammisto, T. (1965) The effect of 5-hydroxytryptamine (serotonin) on retinal vessels of the rat. Acta. Ophthalmol. 43: 430-433.

Thoa, N. B., D. Eccleston, and J. Axelrod (1969) The accumulation of ${ }^{14} \mathrm{C}$-serotonin in the guinea pig vas deferens. J. Pharmacol. Exp. Ther. 169: 68-73.

Uusitalo, H., J. Lehtosalo, J. Laakso, M. Harkonen, and A. Palkama (1982) Immunocytochemical and biochemical evidence for 5-hydroxytryptamine containing nerves in the anterior part of the eye. Exp. Eye Res. 35: 671-675.

Verhofstad, A. A. J., H. W. M. Steinbusch, B. Penke, J. Varga, and H. W. J. Joosten (1981) Serotonin-immunoreactive cells in the superior cervical ganglion of the rat. Evidence for the existence of separate serotonin and catecholamine containing small ganglionic cells. Brain Res. 212: 39-49.

Yousufzai, S. Y. K., R. A. Akhtar, and A. A. Abdel-Latif (1986) Effects of substance $P$ on inositol triphosphate accumulation, on contractile response and on arachidonic acid release and prostaglandin biosynthesis in rabbit iris sphincter muscle. Exp. Eye Res. 43: 215-226.

Zhang, S. Q., G. Terenghi, W. G. Unger, K. W. Ennis, and J. Polak (1984) Changes in substance-P and neuropeptide $Y$-immunoreactive fibres in rat and guinea-pig irides following unilateral sympathetectomy. Exp. Eye Res. 39: 365-372. 